\title{
ANTROPOLOGIA, LITERATURA E INTERDISCIPLINARIDADE NAS CIÊNCIAS SOCIAIS: entrevista com o Professor Valter Sinder
}

Alexandra Santos

Marcia Menezes Thomaz Pereira

\section{APRESENTAÇÃO}

Como parte da nova fase da Intratextos, as entrevistas passam a ter seu caráter modificado na revista. Essas serão organizadas e conduzidas por um aluno, membro do corpo editorial, em parceria com um discente do Programa de Pós-Graduação de Ciências Sociais da UERJ (PPCIS), não vinculado às atividades da revista. Para este volume, entrevistamos um professor do próprio PPCIS, o antropólogo Valter Sinder, quem nos recebeu em sua sala para uma agradável e bem-humorada conversa. Nosso principal objetivo é o de apresentar um panorama do perfil de um membro do corpo docente, bem como dos projetos, linhas de pesquisa e atividades diversas desenvolvidas no programa. O professor Valter é um dos representantes do caráter interdisciplinar das Ciências Sociais. Formado em Ciências Sociais pela Universidade Federal Fluminense, mestre em Antropologia pelo Museu Nacional e doutor em Teoria Literária pela PUCRio, o professor contou-nos um pouco sobre os felizes "acasos" que o ajudaram a construir sua trajetória acadêmica, sobre as principais referências em seu percurso e, também, sobre o casamento entre Antropologia e Literatura, que é fundante em todo processo de sua formação e de seus projetos de pesquisa.

Intratextos: Professor Valter, desde o início de sua formação, é estabelecida uma estreita relação entre as Ciências Sociais e a Literatura. Você faz esse casamento desde sua dissertação de mestrado, cujo título é Antropologia Da Literatura: A Obra Literária como Mediação do Simbólico. Nós gostaríamos de saber um pouco mais sobre sua trajetória.

Valter Sinder: Bem, eu fiz graduação em Ciências Sociais e fui para o Museu Nacional cursar o mestrado em Antropologia. Eu entrei para o mestrado a fim de estudar relações interétnicas, que era minha ideia inicial, estudar sociedades tribais brasileiras. Meu orientador, o professor Eduardo Viveiros de Castro, já era um especialista em etnologia brasileira. À época, eu fiz um curso de relações interétnicas com a professora Giralda ${ }^{1}$, que é uma especialista em assuntos interétnicos. E, quando acabei de fazer o curso, cheguei à conclusão de que não era aquilo que eu queria. Percebi que aquelas não eram mais as questões que gostaria de aprofundar em minha futura dissertação de mestrado. A partir daí, comecei a procurar por outros interesses. Sempre gostei muito de literatura. E dei a sorte de estar trabalhando com o Eduardo, que tem uma formação numa grande área e era aberto o suficiente para receber uma proposta de trabalhar, também, com literatura. O Eduardo é formado em Ciências Sociais pela PUC-Rio e tinha estudado

\footnotetext{
${ }^{1}$ Referindo-se à professora Giralda Seyferth, quem ainda faz parte do corpo docente do departamento de Antropologia do Museu Nacional
} 
com Luiz Costa Lima, um grande nome da Teoria Literária brasileira, quem trabalhou, durante muito tempo, como professor de Sociologia na PUC. No mestrado, eu trabalhei com Antropologia da Literatura, utilizando a teoria estrutural de Lévi Strauss. E foi o Eduardo quem me orientou nesta ideia. Eu comecei a ter que ler teoria literária pois, para fazer uma Antropologia da Literatura, percebi que precisava compreender como o pessoal que é do campo da Literatura reflete e, então, fazer Teoria Antropológica da Literatura. Acabei convidando, para minha banca de mestrado, uma professora do departamento de Literatura da PUC, a Heidrun Friedel Krieger, que ainda faz parte do corpo docente do curso de Letras da PUC-Rio. Ela é especialista em Teoria da Literatura; veio para minha banca como professora convidada e me deu diversas dicas. Fiz minha dissertação de Antropologia da Literatura estritamente a partir de uma discussão teórica, buscando compreender como é possível pensar a Literatura, teoricamente, a partir da Antropologia.

Intratextos: E o seu doutoramento? Você fez doutorado em Teoria Literária na PUC-RIO, com a defesa da tese Configurações da Narrativa: Verdade, Literatura, Etnografia. Como chegou ao departamento de Letras da PUC?

Valter Sinder: Eu cheguei a pensar em fazer o doutorado em Antropologia, mas não no Museu Nacional; gostaria de ver alguma coisa diferente, estudar com outras pessoas. Cheguei a fazer contatos para ir para a Unicamp, para cursar o doutorado em Antropologia lá. Só que, no ano que eu ia prestar a seleção, o programa não abriu. Alguns amigos, então, comentaram da boa receptividade do doutorado em Teoria da Literatura na PUC. Era um programa que tinha vários nomes de professores importantes, mas três desses, já consagrados na teoria literária brasileira. Eu fui aluno dos três: Luiz Costa Lima, Silviano Santiago e o Affonso Romano de Sant'Anna. Eu me lembro que, à época, conversei muito com o Ítalo Moriconi, que virou meu colega de doutorado. Ele entrou no doutorado um ano antes de mim; é formado em Ciências Sociais pela UNB, mas tem mestrado e doutorado em Literatura. Atualmente, o Ítalo é professor da UERJ, de Literatura, e é também o atual Editor Executivo da EdUERJ. Então, eu comecei meu curso na PUC sem ter muita clareza do que faria e acabei refletindo um pouco sobre como a Teoria da Literatura poderia olhar para a Antropologia. Fiz o percurso oposto, já que, no mestrado, eu havia pensado em como a Antropologia poderia olhar para a Literatura. E percebi que já havia várias tentativas em 
se pensar essas questões, várias outras questões estavam sendo colocadas. E acabei conseguindo fazer doutorado sanduíche nos EUA, na Universidade de Notre Dame.

\section{Intratextos: E como foi essa experiência em Notre Dame?}

Valter Sinder: Bom, eu fiquei fora por quase um ano, junto com o Roberto Da'Matta, que era professor de lá na época. Em Notre Dame, me deparei com uma biblioteca que possuía uma extensa bibliografia que vinha sendo publicada nos EUA, exatamente para pensar as questões da narrativa, da literatura. E você descobre que não é tão original, quando percebe que tem com quem conversar (risos). Então, eu mapeei a discussão toda e a minha tese de doutorado foi construída a partir dessa possibilidade que tive de buscar a teoria e discutir, conversar sobre essa temática. Falo que minha trajetória foi construída assim, de vontades. Eu sempre tive, e continuo, tendo uma relação passional com a literatura; leio muita literatura, constantemente estou lendo. E, com essa experiência, eu comecei a pensar: o campo está aberto, o campo existe, o campo está se colocando.

Eu fiz bolsa sanduíche de meados de 1989 até meados de 1990 mais ou menos. O grande seminário, que aconteceu nos EUA, e que acabou culminando na revisão da literatura antropológica e na reescrita da narrativa da cultura, resultando na publicação de The Writing Cuture, ocorreu em 1984. A publicação de The Writing Culture foi em 1986, ou seja, quando eu cheguei nos EUA, em 1989, aquilo ali estava "fervendo". As questões sendo colocadas e eu olhava aquilo e me perguntava: “o que é isso?" . Eu tinha escutado praticamente nada, ou muito pouco, do que estava sendo colocado porque era algo novo. Então quando eu voltei, eu cheguei ao Brasil com uma temática nova em minha cabeça.

Intratextos: Sua trajetória é marcada por muitos privilégios: você trabalhou com Viveiros de Castro, teve orientação no doutorado do Affonso Romano e do DaMatta, foi aluno de Silviano Santiago e Costa Lima. Chegou aos EUA, para o "sanduíche", anos depois do Seminário de Santa Fé. O que nos fala sobre isso?

Valter Sinder: Você sabe que biografia a gente faz a posteriori, não é? (risos) Essa é a história que eu conto para vocês e para mim mesmo. Eu vejo um nexo em tudo que vai acontecendo, mas é também uma porção de acasos que deram certo. E nos Estados 
Unidos foi uma coisa fascinante, eu nunca tinha estudado nos lá. Enfim, você vai costurando essas oportunidades.

\section{Intratextos: E como foi voltar para o Brasil, depois dessa experiência nos EUA?}

Valter Sinder: Eu voltei para o Brasil em 1990 e defendi minha tese de doutorado em 1992. Em novembro de 1997, eu fui para Austin, no Texas, com o projeto de pósdoutorado. Em Austin, existe o maior acervo de biblioteca, latino americano, fora de países latinos. E, além de uma biblioteca central, eles têm uma biblioteca setorial, que é uma coleção chamada Benson Latin America Collection. E, nessa biblioteca setorial, havia todos os livros brasileiros e latino americanos que eu queria. Na biblioteca central, eu encontrava todos os outros livros de que eu precisava. É uma biblioteca fantástica, que proporciona uma condição ótima para trabalhar.

Com isso, naquele momento, eu comecei a trabalhar muito. Eu vinha, já há algum tempo, frequentando um núcleo de trabalho sobre pensamento social brasileiro. Então, comecei a trabalhar com a questão do pensamento social brasileiro dos grandes autores, os chamados ensaístas brasileiros, junto com a questão da literatura. Porque há um entrecruzamento muito interessante dessa fronteira entre a Literatura e a História; entre a Literatura e a Sociologia. E aí aconteceu uma coisa muito curiosa: eu apresentei um trabalho sobre o pensamento social brasileiro no México. E o que aconteceu? Mais uma dessas coincidências boas: o chamado King of Speaker, ou seja, o principal palestrante do congresso, depois que eu apresentei o meu paper, veio conversar comigo e me perguntou se eu não queria marcar um almoço, ou um jantar, com ele. Seu nome é Alfonso de Toro. Ele é chileno, mas estava radicado na Alemanha há 30 anos. Ele é o professor titular da cadeira do Instituto de Romanística da Universidade de Leipzig, na Alemanha. Nós conversamos sobre o paper e ele acabou me convidando para ser professor visitante na Universidade.

\section{Intratextos: Foi assim que você foi para a Alemanha?}

Valter Sinder: Sim. Mas no início, eu achei que fosse "coisa de brasileiro", não é? (risos) Mas se passaram quatro meses e chegaram todos os papeis para eu ir para a Alemanha. Acabamos por fazer um convênio entre a Universidade de Leipzig e a UERJ. 
E, em 1998, eu fui para a Alemanha dar um curso, em português, no Instituto de Romanística. Depois, voltei em 1999; dei aula por dois anos seguidos. O convênio continuou existindo. Em 2000, indiquei o professor João Trajano e, no ano seguinte, foi a professora Helena Bomeny.

Intratextos: Em 2002, você publicou seu livro. Apesar de ele ser uma publicação oriunda da sua tese de doutoramento, você deu um intervalo de dez anos para a publicação. Como isso ocorreu?

Valter Sinder: Então, em 2002 o livro foi publicado pela editora alemã. Onde eu dei aula, na Universidade de Leipzig, tem uma coleção que se chama Teoria e Crítica da Cultura. O editor chefe, que é o professor Alfonso de Toro, tem um comitê editorial que só publica teses acadêmicas, nas suas línguas originais. E o que aconteceu? Eu tinha escrito a minha tese em 1992. O livro, que saiu a partir da tese, teria, em si, incorporados dez anos. Ou seja, ou eu escrevia uma coisa nova, ou eu não mexia no texto. Mas se eu não mexesse no texto, ele ficaria datado demais. Então o que eu fiz? Eu não mexi no texto, mas mexi nas notas de pé de página. Então, eu atualizei a bibliografia através das notas. Para deixar claro que, primeiro, é um texto de 1992. Segundo, que a discussão permanece atual.

Intratextos: Professor, existe hoje, na academia, sobretudo nos concursos de ingresso para a carreira docente, a tendência de se buscar profissionais especializados. Pensando nessa realidade, o casamento entre Antropologia e Literatura, que marca sua trajetória, em algum momento fez com que você tivesse alguma porta fechada?

Valter Sinder: Eu comecei a trabalhar nessa área, que não é nem interdisciplinar, mas transdisciplinar, já que atravessa vários campos. Eu me formei em um momento propício para esse tipo de questão. Como eu sempre gostei muito de ler teoria - teoria antropológica, teoria literária, teoria sociológica, filosofia, epistemologia. A minha formação pessoal e o campo de reflexão que eu escolhi, se fizeram propícios para essa questão interdisciplinar e transdisciplinar. E, assim, aos poucos eu comecei a trabalhar nessa área, dando cursos sobre teoria, metodologia, e/ou sobre pensamento social brasileiro. Eu lia os autores dessas áreas para compará-los ou para pensá-los no campo da Literatura, da narrativa e na teoria. Então, eu não tenho essa impressão. Pelo contrário, eu frequentei, durante muito tempo, congressos em outras áreas, tanto na ANPOCS, na ABA, como na ABRALIC, que é Associação Brasileira de Literatura 
Comparada. Assim como eu já apresentei trabalho na ANPUH, que é de História. Hoje em dia, eu suponho, existe uma abertura maior. Ao invés de você trabalhar com a questão disciplinar, você tem questões temáticas. Então, se tem uma linha na História onde tem temas que você trabalhe, geralmente, você é bem-vindo para conversar, para discutir sobre Sociologia, sobre Política, etc.

Intratextos: Mas não parece um contrassenso que, enquanto nos debates, nos congressos, nos grupos de trabalho se consiga passear pelas diferentes áreas, na hora de se prestar um concurso, seja exigida uma especialização? Porque você conseguiu construir todo esse percurso, mas você já era professor daqui (da UERJ) e da PUC quando fez suas escolhas. De repente, se você fosse fazer um concurso depois do seu doutorado...

Valter Sinder: ... Ia ser difícil. Hoje, quando você vai fazer um concurso, você tem que fazer, claramente, orientado para uma área. Não tem a ver com sua formação acadêmica, stricto sensu, mas dentro de sua formação, você precisa pensar em temáticas. Mesmo se eu quiser dar aula em Letras, e eu tenho diploma para dar aula em Letras, eu nunca serei aceito. Primeiro porque eu não conseguiria; segundo porque eu não tenho o conhecimento necessário. A minha passagem pelo departamento de Letras foi excelente, mas, a todo momento, eu estava ali olhando para a Antropologia.

O que eu acho mais importante notar é que, mesmo que você passe por uma formação variada, aos poucos, os campos temáticos nos quais você está se inserindo vão se delimitando. Isso é que se vai marcar a sua trajetória, vai marcar os seus interlocutores. E é isso que, aos poucos, vai direcionar sua formação. Assim como hoje, por exemplo, nos meus grupos de trabalho, na ANPOCS, ou na ABA, ou em algum outro seminário, eu convido colegas meus que são da área de Literatura, mas que têm uma conversa muito grande com a gente, eles também me convidam, porque é interessante você ter esse tipo de convivência. A gente tem uma mania, e não por um acaso, de considerar as Ciências Sociais como sendo a Sociologia, a Antropologia e Política. E não necessariamente é. Porque, às vezes, você está na Antropologia, e conversa mais, como é o meu caso, com a Literatura. Ou com a Filosofia, ou com a Educação... Hoje em dia, a gente tem alguns antropólogos que estão no departamento de Educação, porque trabalham com isso. Você tem vários departamentos, nos quais os antropólogos estão colocados, que não têm só a ver com a sua formação, mas com a sua formação e o seu campo temático. Assim como quem trabalha com Política pode ter alguns diálogos 
voltados para Direito, por exemplo. Eu, particularmente, acho que os cursos de Ciências Sociais, de graduação, deveriam ter uma abertura maior de conversa interdepartamental. Os departamentos têm autonomia para dizer quais são as matérias consideradas fundamentais para formar um cientista social. Então, se você resolve que lingüística é uma coisa importante, ou, então, introdução ao direito, por exemplo, o que significaria isso? Significaria que cada Universidade tem uma formação básica das Ciências Sociais, mas poderia orientar a formação sobre os alunos, diretamente relacionada ao corpo docente que estivesse ali presente. Isso seria muito interessante, uma vez que a tendência hoje é, cada vez mais, na nossa área, a de aumentar essa possibilidade de conversa com outras matrizes disciplinares.

Intratextos: Professor, nesse casamento entre Antropologia e Literatura, quais são os nomes, ou os trabalhos, que você hoje destacaria? Quais são as referências neste campo?

Valter Sinder: Você tem autores clássicos que trabalharam no campo da Literatura com as Ciências Sociais, como o Hayden White que trabalhou na fronteira da Literatura com a História. Ele é fundamental. Você tem autores franceses, como Derrida, Deleuze, Foucault. Esses são autores que não necessariamente trabalham com essa questão, mas que estão próximos. Roland Barthes, um dos nomes de referência fundamental na Semiologia, no trabalho com a Literatura, por exemplo. Em Ciências Sociais, você tem tanto quem trabalhe com Sociologia da Literatura, como quem trabalhe com uma questão mais da Antropologia da Literatura. No Brasil, Luis Costa Lima, Silviano Santiago, Affonso Romano de Sant'Anna são grandes nomes de referência. O Roberto DaMatta, durante um tempo, publicou sobre Literatura. Ele tem um livro que é muito interessante que se chama Ensaios de Antropologia Estrutural, no qual faz uma análise brilhante de um conto de Edgard Allan Poe. Magnífica!

Tem um texto, do próprio Eduardo Viveiros de Castro com o Ricardo Benzaquén de Araújo, sobre Romeu e Julieta, que, na verdade, é sobre teoria antropológica, mas a questão da literatura está presente. Tem a tese da Regina Abreu sobre o Euclides da Cunha que também é muito interessante. Tem o José Reginaldo Gonçalves, que é professor do $\mathrm{IFCS}^{2}$, e trabalhou nesse campo, mas com a questão da retórica, da

\footnotetext{
${ }^{2}$ Instituto de Filosofia e Ciências Sociais da Universidade Federal do Rio de Janeiro.
} 
narrativa. É através das figuras da Literatura que ele trabalha com a questão de patrimônio. A tese do Reginaldo se chama A Retórica da Perda, que é super interessante. Na Literatura, Flora Süssekind é super interessante. Ela é do campo da Literatura, mas tem uma abordagem mais sociológica, interdisciplinar. Ela tem um livro que se chama $O$ Brasil não é longe daqui, que é muito interessante. Eu não gosto de citar nomes, mas esses são alguns.

Intratextos: Em seu texto $A$ reinvenção do passado e a articulação dos sentidos: $o$ novo romance histórico brasileiro, publicado em 2000, você, ao se referir ao projeto literário nacional romântico, afirma que "a narrativa da nação será realizada em conjunto pela escrita da história e da literatura. Onde fatos e fontes não puderam ser utilizados, caberá à ficção preencher as lacunas do nosso passado mediante a criação de tramas ficcionais". Mas, no caso do etnógrafo de campo, que busca mapear uma narrativa de determinado grupo social, como seriam preenchidas tais lacunas?

Valter Sinder: A primeira coisa que se deve entender é que ficção não é mentira. Clifford Geertz fala que a etnografia é uma ficção, e que a ficção é entendida como fictio, que é do latim e significa algo que é produzido. Qualquer narrativa é produzida. Não há uma narrativa que não seja, de alguma maneira, ficcionalizada. Porém, o pressuposto é que construir uma ficção não é inventar, muito pelo contrário. A idéia é ter a clareza de que sempre quando a gente produz uma narrativa, esta narrativa é endereçada, é produzida. Ela é feita. E aí, depende do campo em que você está produzindo. Se você vai trabalhar com romances, ou se você vai trabalhar em campo, no sentido de pegar a narrativa do sujeito com qual você trabalha, você vai ter que fazer uma costura, vai ter que fazer uma montagem. Vai ter que fazer uma seleção, dar um nexo. E isso é uma produção narrativa como outra qualquer. Mas é preciso ficar claro que, em vários momentos, necessariamente, somos nós que estamos costurando, estamos produzindo aquele sentido. Pois, se você não tiver esta clareza, você vai cair numa ilusão, que é a ilusão do fato, de um acontecimento mesmo, de uma verdade positivista.

O texto do Helio Silva, A situação etnográfica: andar e ver, é uma reflexão sobre o trabalho etnográfico, do trabalho de campo, do que é o olhar, do que é atentar o olhar para o campo, percebendo que você faz parte dele também. Você também é o outro no trabalho de campo, você também é um sujeito. Neste sentido, eu não vejo diferença em trabalhar com a Literatura, fazer o campo na Literatura, ou fazer o campo no campo 
tradicional, em outros espaços, em qualquer tipo de espaço. Mas aí é uma questão pessoal.

Intratextos: Para finalizar, como você se definiria? Você é antropólogo que estuda Literatura ou um teórico literário que trabalha com o escopo da Antropologia?

Valter Sinder: Eu me defino como um antropólogo. A minha identidade profissional é de antropólogo. Eu fiz doutorado em Literatura Comparada, mas fiz pós-doutorado em Ciências Sociais. E, a todo tempo, estou nessa área de Ciências Sociais. Eu sou um antropólogo que trabalha a partir da Literatura, com a Literatura, junto da Literatura. Eu não faço uma Antropologia da Literatura, não é isso. É a partir dela; junto com ela. Eu não tomo a Literatura como meu objeto de reflexão. Não é isso. A própria Literatura, a Teoria da Literatura é constitutiva da minha maneira de fazer Ciências Sociais. A Literatura não é um instrumento. Quando a gente usa como instrumento é como se você usasse como meio. Ao contrário, uma das formas possíveis de fazer antropologia é através dessa perspectiva das narrativas. É uma das formas, mas não é exclusiva. Eu entendo, perfeitamente, que algumas pessoas possam escolher refletir antropologicamente, legitimamente, tomando outros pontos de partida, outras questões e tudo mais. Não há uma antropologia, uma sociologia. 